\title{
neofilolog
}

Czasopismo Polskiego Towarzystwa Neofilologicznego

ISSN 1429-2173, 2018, NR 51/2, 225-236

http://dx.doi.org/10.14746/n.2018.51.2.8

http://poltowneo.org/

\author{
Anna Wierciak \\ Jagiellonian University, Jagiellonian Language Centre \\ https://orcid.org/0000-0002-9868-3297 \\ anna.wierciak@uj.edu.pl
}

\section{STUDENT-GENERATED COMMUNICATION ACTIVITIES IN AN ENGLISH FOR SPECIFIC PURPOSES COURSE}

\begin{abstract}
Designing English for Specific Purposes (ESP) courses is a challenging task. The teacher often has to cope with time constraints, shortage of resources as well as his or her insufficient knowledge of a given field of study. Students enrolled in a course are often consulted about the source of materials for instruction. The process of developing ESP tasks can be made easier and less time-consuming by means of employing studentgenerated communication activities which draw on learner-based approaches to teaching. The paper contains a collection of student-generated tasks that can be successfully used at the preparatory, follow-up or main stage of an ESP class. In the author's teaching context on numerous occasions they have triggered lively exchanges between students: discussion, brainstorming, or negotiation. Student-generated activities naturally develop collaboration and autonomy, which are essential in the workplace environment. Just like communication skills, they have to be taught explicitly due to the fact that in the area of soft skills there exist considerable differences at the personal and culture-specific level. Finally, since students' specialist knowledge is usually much better than that of the teacher, student-generated activities tend to be to the point, up-to date, or more precise with respect to the course objectives.
\end{abstract}

Keywords: course design, authentic materials, student-generated activities, communication, collaboration, autonomy

Słowa kluczowe: planowanie kursu, autentyczne materiały, ćwiczenia tworzone przez uczniów, komunikacja, współpraca, autonomia 


\section{Introduction}

Teachers of English at the university level face the challenge of designing courses and developing tasks and materials for teaching English for Specific Purposes (ESP) to students who represent different professional groups. This is a challenge for the teacher's creativity which often has to face some limitations. Firstly, there are time constraints as the teacher often teaches concurrently many groups with different academic/professional profiles. Secondly, designing courses and developing teaching materials constitute only a fragment of the teaching methodology course offered to students of English studies and may prove insufficient for the purposes of creating language courses for specialist professional groups. The teacher may need to develop his or her skills further in this area on his or her own. What is more, there is a shortage of ready-made ESP resources by leading publishing houses specifically designed for narrowly specialised professional groups at higher language levels and with considerable expertise in their areas of interest. Even if an ESP teacher happens to find suitable resources, the information they provide becomes quickly outdated, especially in technical English courses (Gajewska-Skrzypczak, 2016). Finally, the teacher's limited knowledge of a given field of study might be an obstacle in course planning. Very often "ESP teachers are also just students of the target field" (Anthony, 2007: 3).

In view of these limitations, teachers of English at the university level look for ways which could help them design, plan and implement English for Specific Purposes courses, especially those dedicated to graduate level students who have considerable experience in language learning and should take an active part in planning a syllabus which is to be tailored to their needs.

At the basic level of instruction materials and classroom activities, limitations in course design related to time constraints, lack of ready-made materials and insufficient knowledge of a given field of study on the teacher's part may be overcome by means of student-generated communication tasks and activities based on authentic materials of students' choice which are relevant to their experience and thus to the course objectives. The idea is obviously not new. It originated at the time when there was a shortage of instructional materials, there was no internet and the use of modern technology in education was expensive and not widely available. In the last decade of the 20th century Sheelagh Deller published Lessons from the Learner (1990), the educational context in Poland inspired the book entitled Learner-Based Teaching (Campbell \& Kryszewska, 1992) and later Luke Meddings and Scott Thornbury developed a teaching method and philosophy called Teaching Unplugged. Teaching Unplugged (Meddings, 2011; Thornbury, 2017) implies that 
lessons are conversation-driven, printed materials-light and focused on the language that emerges from communication.

The following paper contains a collection of student-generated communication activities that can be successfully used at the preparatory, follow-up or main stage of an ESP lesson. According to Skills for Today, a paper published by Pearson together with the Partnership for 21st Century Learning (Metusalem, Belenky \& DiCerbo, 2017), the most important communication skills include interpersonal communication, active listening and oral presentation/public speaking. The majority of the tasks presented in this paper have been inspired by teaching methods which try to cope with the problem of limited resources and draw on the learner as a resource. Despite the fact that some of them date back to the 1990s, the task scenarios they recommend may inspire teachers today and make the process of developing ESP activities easier and less time-consuming.

In her ESP courses the author has used most of the student-generated activities as collaborative digital tasks in order to reflect the collaborative nature of the present-day workplace. English is used as the lingua franca in the presentday workplace due to globalization and globalization itself "has been driven by advances in technological and communications innovations" (Flowerdew, 2013: 340). English for Specific Purposes classes are a perfect opportunity to engage students in tasks such as meetings, negotiations, suggestion making, as well as speaking in public. All these social events require group members to use and develop the basic subskills of collaboration and teamwork and they may be enhanced by digital communication tools. In Skills for Today (2017:6) Lai, DiCerbo and Foltz remark that "there is a long-standing concern that institutions of higher education are not producing graduates with the collaboration skills needed to succeed on the job." That is why collaboration skills may become an element of the continuous evaluation of students in communication activities. Planning student-generated communication activities in an ESP course begins at the needs analysis stage which, according to Flowerdew (2013), should take into account technologization and transnationalization.

\section{Needs analysis - the first student-generated activity in an ESP course}

The basic tool which can make designing such a course easier is the needs analysis conducted at the beginning of the course in a given academic/professional group. The needs analysis is the starting point for determining the aims, and the content, the methods and techniques which lead to the achievement of these aims. Students may not be aware of all their language needs relating to taking part in academic and professional life, hence it is advisable that the 
teacher asks specific questions in the needs analysis which will lead students to reflect on various aspects of the course. The teacher should ask for students' suggestions about the aims and the content of the course, the skills they would like to develop, the types of language tasks they would like to do, or relevant sources and authentic materials on which the coursework will be based. The teacher is advised to adopt an active role at the needs analysis stage by not only suggesting the elements indispensable in successful syllabus design, but also by recommending specific aims, tasks, skills and materials, for example, those useful in academic life, or those useful for employability purposes. These include, among others, clear communication, collaboration and teamwork. The active role of the instructor is strongly recommended due to the fact that students have insufficient knowledge of the process of syllabus design or evaluation of achievement of aims. It is the teacher who determines, on the basis of a placement test, the grammatical elements useful for students' academic and professional purposes. On the other hand, it is easier for students to specify the situations, the content, language functions, means of communication and tasks which they will encounter in a given professional context. It is often the case that the syllabus of a foreign language for specific purposes course contains the various elements mentioned above and is mixed in character, as it tries to meet the needs and expectations of the majority of participants. Dubin and Olshtain (1986) stress the advantages of such course design by referring to its eclectic and flexible nature. However, the teacher also needs to understand the limitations of planning a course with a mixed syllabus. Susan Feez remarks that it may be difficult to design an appropriate sequence of elements in such a syllabus, which may have a negative influence on the course progression and coherence (Feez, 1998). Taking this into consideration Dubin and Olshtain (1986) suggest that it may be necessary to make corrections to the syllabus while the course is in progress.

Conducting the needs analysis can naturally become one of the first communication activities in the language course. Due to its collaborative nature, this task lends itself to developing meeting and negotiation skills. A wellstructured needs analysis is guided by the instructor who may feed in language for discussion, negotiation and suggestion giving. Remembering useful phrases may be easier for students, as is the case with any "sequence of words which native speakers feel is the natural and preferred way of expressing a particular idea or purpose" (Lindstromberg \& Boers, 2008: 7), if they reflect on the grammatical or lexical patterns used in them and if they use them meaningfully and creatively many times throughout the course. The results of students' negotiations might be recorded instantaneously with the help of a digital tool called flask.io which enables students to create to-do lists and to save 
them for further reference. Needs analysis is a perfect opportunity for the teacher to stress the importance of communication skills in English for employability and announce how they will be systematically developed, reviewed and continuously assessed throughout the course.

\section{Student-generated communication activity for the pre-reading or pre-listening stage of an English for Specific Purposes class}

Before reading or watching authentic instructional material, students may be asked to generate content-related questions and discussion questions. In pairs they formulate questions to which they expect to get answers while reading a text or watching a video. The results of collaboration can be stored in the virtual chatroom open for this purpose, such as todaysmeet.com, and displayed on the screen. Only well formulated questions should be accepted by the teacher. The reasons behind the rejection of incorrectly formulated questions need to be discussed with the class before they are eventually deleted from the chatroom. In this way some questions are eliminated at the beginning of the activity. After the first listening, watching or reading, students check how many of their questions were answered in the video/recording/text. The students who have generated the largest number of questions which are answered in the audio or visual material win the competition. After the second listening, watching or reading the whole group is asked to answer the winners' questions first and, if time allows, other useful questions generated by the rest of the group. The questions which are not answered in the authentic material chosen for the lesson but are relevant to the topic of the lesson might be discussed in a follow-up discussion.

Generating questions seems to be a more challenging task than brainstorming single words as it is easier to predict words than formulate ideas/questions. On the other hand, it is more difficult to record which words have been used, e.g. in an authentic video material if the tapescript is not available. It is definitely easier to keep track of ideas which have been presented in the recording.

To make generating questions easier, the teacher may present students with examples of effective and diverse questions, which will prompt longer responses than yes/no responses. Questions may be divided into factual questions (who? what? where? when? how much?), questions about causes or consequences (why? what are the consequences of...?), questions about the main idea (what is the text/recording about?), questions about the context (what circumstances was the text/recording created in?), questions about the author's reader's/viewer's opinion (what is his/her opinion about..?), speculation questions (what would the author/reader/viewer do if...?) or questions which require 
reading between the lines. In the author's teaching context undergraduate or graduate students represent B2 or higher levels, which enables them to formulate and answer basic as well as complex questions. One of the rules of the activity might be to create only indirect questions. More examples of effective questioning techniques have been listed in one of a series of articles on teaching English with minimal resources (Maley).

Student-generated questions may be an effective springboard for several-minute long discussions on topics related to the students' field of study. The students, who are experts in the field, take care of the factual aspects of the discussion. On the other hand, the teacher who monitors language accuracy and appropriateness may use the discussion time for feeding in language functions useful in the given context and for rewarding those participants who have used such expressions correctly.

\section{Student-generated communication activity for the pre-writing stage of an English for Specific Purposes class}

The following activity can precede the writing of a for/against essay. Group members generate arguments related to a given topic using the online chatroom called www.tricider.com. The chatroom offers space for generating pros and cons next to the main idea of the essay and for voting for those which are most relevant to the topic. In the course of the lesson, students are able to see and evaluate all the ideas their classmates have generated by ranking the most effective arguments. The teacher may ask them to discuss the ideas further by giving examples. These days many students confuse causes with results or advantages with disadvantages, so the activity gives the teacher an opportunity to ensure that the ideas are logical and coherent with the purpose of the writing task. At the end of the class, the teacher sends the link to the generated pros and cons via email so that students can have some input ready when they start composing their essays.

\section{Student-generated communication activities for the follow-up stage of an English for Specific Purposes class}

\subsection{Translation task}

The following task requires pairs of students to translate key sentences from an authentic text or recording into Polish on a piece of paper. Each pair gets a different sentence to translate printed out at the bottom of an A4 piece of paper. Their translation should appear at the top of the page. When it is ready, 
learners are asked to fold the paper in such a way that their translation cannot be seen. The pieces of paper are passed on to another pair, who translate the sentence located at the bottom of the page from English into Polish again (without looking at the previous pair's version). The activity continues until there are at least 5 Polish versions of the original English sentence. At the end of the activity students compare different translations. By that time they are not only familiar with the key vocabulary related to a given topic, but are also able to select the best translation and discuss the way the translation process changes the original sentence as well as potential pitfalls of word-by-word translation. This activity was inspired by Campbell and Kryszewska (1992: 84).

\subsection{Defining task}

At the follow up stage of an ESP lesson, students may also be asked to revise the key words related to the topic of the class by generating 15-20 such words with the help of the collaborative digital tool answergarden.ch. At the generating stage students can immediately see the words on the screen. Next, students are divided into pairs. At this stage one person in a pair sits with his or her back to the screen. The partner who can see the screen provides the definition of one of the key words in such a way that the other person is able to guess which word he or she has in mind. In the next round of the activity students swap roles. The game gets even more interesting if learners compete in groups. The task is a variation of a popular activity called back to the board, described in one of a series of articles on teaching English with minimal resources (Tennant, n.d.). Its major advantage is the fact that students practise formulating ideas related to their field of study in a precise manner.

\subsection{Collaborative mind maps}

Another step in developing clear communication skills and teamwork might require students to role-play a meeting in which they contribute to generating a mind map of the text they have read. They are assigned the roles of the chairperson, mind map creators and ideas contributors. The mind map is generated by means of bubbl.us, a digital online mind map generating tool. The tool offers an opportunity to generate mind maps in the form of grids, trees and circles. Students can suggest not only the ideas which could be included, but also can negotiate whether theirs is the main idea or a subordinate one as well as where it should be placed on the map. 


\section{Student-generated presentations}

Giving a presentation is a popular task used in English for Specific Purposes classes, often planned as the main part of the lesson. Even at the graduate level students still experience difficulties when speaking in public. Both the planning and the delivery stages of a presentation need polishing. Sooner or later in their professional life students will be asked to speak in front of fellow students or employees. The needs analysis helps determine the topics students would like to give presentations about. Since it is necessary to ensure smooth progression and internal coherence in an ESP course, the plan of students' presentations should be established as early as the course programme is agreed upon. Questions generated by fellow students relating to the topic of the presentation may be a complementary element to the presentation in the form of either a starting point for the presentation by a student-expert in a given field, or in the form of a follow-up question and answer session. In this way the process of preparing the presentation becomes collaborative, as the presenter-expert can anticipate fellow students' expectations, or potential questions, and make sure the communication between him or her and the audience is effective.

\section{Feedback on and assessment of students' performance in student-generated communication activities}

Communication activities generated by students may be successfully employed in ESP classes as a regular classroom routine. As such they should also become opportunities for students' continuous assessment. It seems logical that student-generated tasks naturally promote peer feedback, not only feedback from the teacher. In fact, like needs analysis, peer feedback is another element in the cycle of developing active listening and collaboration.

Rubrics for assessing presentation skills are widely available and a lot of them take into account peer evaluation (de Chazal \& Moore, 2013). It is advisable that peer evaluation is included in online customized surveys such as the ones offered by surveyplanet.com, which can provide the speaker with immediate feedback after his or her presentation. Collaborative feedback lets the presenter see if he or she has been able "to model the mind of the receiver in order to produce a message that the receiver is likely to interpret as intended" (Metusalem, Belenky \& DiCerbo, 2017: 11). In other words, the author of the presentation has a chance to reflect whether the message has been structured in a way which effectively addresses the audience's knowledge, beliefs and culture.

Other student-generated communication activities presented in this paper require the teacher to create his or her own students' assessment rubrics. For 
example, for the task of generating content-related questions and discussion questions the instructor may assign a specific number of points for every correctly formulated question, variety in question formation and students' contributions to discussing the content of the authentic material and topic-related problems. In brainstorming tasks the teacher's assessment procedure should counteract the common student strategy of using sentence fragments, or unfinished affirmative sentences for the purpose of asking questions, or making suggestions. Very often students neglect social conventions and do not take the time or the effort to formulate polite or tentative, well-pronounced queries or proposals. Students ought to be rewarded for meaningful and appropriately formulated contributions to collaborative brainstorming sessions. The teacher's task of remembering student's contributions is easy these days, as students can not only take part in a conversation, but can also be made responsible for keeping a record of their own proposals, or suggestions in real time with the help of collaborative digital tools such as pl.padlet.com, or conceptboard.com, both of which are most convenient to use if an ESP class happens to be scheduled in a computer room.

In the translation tasks, apart from the feedback given by fellow students who select the best translation, the teacher should assess students' contributions in terms of accuracy and use of natural lexical combinations by assigning points for task achievement, word order, grammar, vocabulary choice and range.

For collaborative tasks such as the translation task described above, a hybrid assessment procedure is recommended by Lai, DiCerbo and Foltz (2017: 20) since apart from "task demands, there are other considerations in designing assessment tasks such as group size, identifiability of individual contributions, and group composition." A hybrid assessment combines evaluation of group performance as well as individual participation in collaboration. Gathering evidence of individual contribution to a collaborative task may be based on the teacher's observation and, if time allows, students' own reflections on their involvement in the teamwork. Indicators of successful collaborative behaviour include, depending on the type of communication task, readiness to share ideas, turn-taking, asking for other people's points of view, handling miscommunication, identifying elements of problem-solving, or willingness to negotiate win-win solutions and reach consensus. The list of behaviour types which foster collaboration is much longer and has been compiled by Lai, DiCerbo and Foltz (2017) on the basis of recent studies in this field. It seems easier to assess selected collaboration indicators if students work in one big group and have the clearly defined roles of a meeting/discussion chairperson, a note-taking person, or meeting/discussion participants, etc. 


\section{Conclusion}

The author of this article has frequently used student-generated communication activities in her coursework. The preparations for these tasks include, firstly, the choice of an authentic text, recording or video. The choice is guided by the syllabus negotiated with the students at the beginning of the course. Secondly, the planning stage involves making a list of useful expressions students will need during an activity. The truth is that these expressions need to be reviewed systematically if the participants' communication abilities are to resemble those of native speakers of English. Thirdly, the teacher needs to plan in advance how individual students' performance and group performance are going to be evaluated. Different collaboration and communication subskills require different assessment rubrics, which have to be announced to students in advance. If learners are aware how their contributions are going to be evaluated and how often this is going to take place, they tend to put more effort into performing the tasks and eventually in developing skills useful for employability. In the author's teaching context, on numerous occasions, well planned student-generated communication activities inspired pair and group collaboration as well as lively exchanges between students. Activities based on questions, suggestions or proposals produced by students are particularly highly recommended as they offer practice in effective direct or indirect question formation, which may be a challenging task both in the mother tongue and in the foreign language. Apart from interpersonal and collaboration skills, student-generated communication activities also develop autonomy, another essential skill in the workplace environment. Since students' specialist knowledge is usually much better than that of the teacher, studentgenerated activities tend to be to the point, up-to-date, or simply more pertinent to course or lesson objectives.

The student-generated oral communication tasks described in this paper might be naturally followed by collaborative written communication tasks, for example, writing email exchanges, memos or essays. Thanks to collaborative digital tools, the outcomes of student-generated communication activities can be saved for further reference and used as starting points for designing new tasks with clear assessment criteria.

\section{REFERENCES}

Anthony L. (2007), The teacher as student in ESP course design (in) Wykład inauguracyjny na sympozjum pod tytułem 2007 International Symposium on ESP \& Its Applications in Nursing and Medical English Education. 
Student-generated communication activities in an English for specific...

Kaohsiung. Online: http://www.laurenceanthony.net/research/2007100 5_06_fooyin_keynote/20071005_06_fooyin_keynote_proc.pdf [access date: 02.08.2018].

Campbell C., Kryszewska H. (1992), Learner-based teaching. Oxford: Oxford University Press.

de Chazal E., Moore J. (2013), Oxford EAP. A course in English for academic purposes. Oxford: Oxford University Press.

Deller S. (1990), Lessons from the learner. London: Longman.

Dubin F., Olshtain E. (1986), Course design. Cambridge: Cambridge University Press. Feez S. (1998), Text-based syllabus design. Sydney: National Centre for English Language Teaching and Research.

Flowerdew L. (2013), Needs analysis and curriculum development (in) Paltrige B., Starfield S. (eds), The handbook of English for specific purposes. Chichester: John Wiley \& Sons, Inc, pp 325-346.

Gajewska-Skrzypczak I., Sawicka B. (2016), Język specjalistyczny na uczelni technicznej. Refleksje nauczycieli praktyków (in) "Języki Obce w Szkole", No 3, pp. 5.

Lai E., Dicerbo K., Foltz P. (2017), Skills for today: what we know about teaching and assessing collaboration. London: Pearson. Online: http://www.p21.o $\mathrm{rg} /$ storage/documents/Skills_For_Today_Series-Pearson/Collaboration_ White_Paper_FINAL.pdf [access date: 27.03.2018].

Lindstromberg S., Boers F. (2008), Teaching chunks of language. Rum, Austria: Helbling Languages.

Maley A. Using minimal resources: using questions. Part 1. Online: http://www .onestopenglish.com/methodology/minimal-resources/skills/minimal-res ources-using-questions-part-1/146548.article [access date: 18.09.2017].

Meddings L. (2011), 20 steps to teaching unplugged. [seminar] British Council. Online: https://www.teachingenglish.org.uk/article/20-steps-teaching-un plugged [access date: 15.09.2017].

Metusalem R., Belenky D.M., DiCerbo K. (2017), Skills for today: what we know about teaching and assessing communication. London: Pearson. Online: http://www.pearsonlearningnews.com/wp-content/uploads/2018/02/communication-skills-final.pdf [access date: 27.03.2018]. Tennant A. (2017), Minimal resources: teaching vocabulary. Online: http://ww w.onestopenglish.com/methodology/minimal-resources/vocabulary/m inimal-resources-teaching-vocabulary/146544.article [access date: 18.09.2017]. Thornbury S. (2017), M is for manifesto. [Blog] An a-z of ELT. Online: https://scotth ornbury.wordpress.com/tag/teaching-unplugged [access date: 17.09.2017]. 


\section{NETOGRAPHY}

https://answergarden.ch [access date: 09.10.2017]

https://bubbl.us [access date: 18.03.2018]

https://conceptboard.com [access date: 18.03.2018]

https://flask.io [access date: 23.03.2018]

https://pl.padlet.com [access date: 09.09.2017]

https://surveyplanet.com [access date: 25.03.2018]

https://todaysmeet.com [access date: 09.10.2017]

https://www.tricider.com [access date: 09.10.2017] 